\title{
Play Activity: To Increase Fundamental Movement Skill for Children with Mild Mental Retardation
}

\author{
M. Haris Satria ${ }^{1, *}$, Bangkit Seandi Taroreh ${ }^{1}$, MargarettaIneke Melynda ${ }^{2}$, Novri Asri $^{3}$ \\ ${ }^{1}$ Department of Sport Education, Universitas Bina Darma, Palembang, Indonesia \\ ${ }^{2}$ Nursing Pavilion, RSUD dr. H. Moh. Rabain, MuaraEnim, Indonesia \\ ${ }^{3}$ Department of Sport Education, Universitas Islam Kalimantan Muhammad Arsyad Al Banjari, Banjarmasin, Indonesia
}

Received September 22, 2020; Revised November 27, 2020; Accepted December 22, 2020

\section{Cite This Paper in the following Citation Styles}

(a): [1] M. Haris Satria, BangkitSeandi Taroreh, MargarettaIneke Melynda, Novri Asri, "Play Activity: To Increase Fundamental Movement Skill for Children with Mild Mental Retardation," International Journal of Human Movement and Sports Sciences, Vol. 8, No. 6A, pp. 1-10, 2020. DOI: 10.13189/saj.2020.080701.

(b): M. Haris Satria, BangkitSeandi Taroreh, MargarettaIneke Melynda, Novri Asri (2020). Play Activity: To Increase Fundamental Movement Skill for Children with Mild Mental Retardation. International Journal of Human Movement and Sports Sciences, 8(6A), 1-10. DOI: 10.13189/saj.2020.080701.

Copyright $\bigcirc 2020$ by authors, all rights reserved. Authors agree that this article remains permanently open access under the terms of the Creative Commons Attribution License 4.0 International License

Abstract This research aims to, 1) develop a draft of play activity: to increase fundamental movement skill for children with mild mental retardation and 2) obtain empirical data on the effectiveness of the results of play activity: to increase fundamental movement skill for children with mild mental retardation. This research is the development of (research and development). The sample in this study is retarded children in SD SLB C Karyalbu, SD SLB C YPAC and SD SLB B Pembina. The result of research and development as well as the procedures, the resulting product is a model of instruction play activity: to increase fundamental movement skill for children with mild mental retardation currently consists of 46 model variations. From the results, small group test showed that model of play activity: to increase fundamental movement skill for children with mild mental retardation, this good and can be used by students and teachers in SD SLB C in Palembang. From the results field try group test stated that the products developed can be used by children with mild mental retardation however still needing guidance. The effectiveness test product development showed a significant improvement to the fundamental movement skills (locomotor, non-locomotor and manipulative) children with mild mental retardation, and the results large-scale trial stated that the products developed can be used without guidance. Suggestions on this research are that this product can be used as one way to increase fundamental movement skills for children with mild mental retardation and specific to the teacher that this product can be used as material to instruct the basic motion of matter.

Keywords Play Activity, Fundamental Movement Skill, Mild Mental Retardation

\section{Introduction}

Mental retardation is a child who has a level of intelligence below the average normal child. This is in line with the opinions of Armatas saying that "Mental retardation (MR) is a genetic disorder manifested in significantly below average overall intellectual functioning and deficits in adaptive behaviour. Mental retardation is a particular state of functioning that begins in childhood and is characterized by decreased intelligence and adaptive skills and also is the most common developmental disorder [1]. Furthermore, according to Kemis and Ati saying that a child of mental retardation is an individual who significantly has intelligence under normal intelligence with an equal or lower IQ score of 70[4]. According to Genewa in Widati and Murtadlo argues that mental retardation is a state of stalled or incomplete mental development characterized by skill constraints during developmental period so that it 
affects all levels of intelligence, such as cognitive, language, motor, and social skills [7]. According to Kemis and Ati, there are some classifications of children with mental retardation including (1) Classification based on learning needs consists of (a) the level of borders in education called slow learner with IQ 70-85, (b) educable mentally retarded with IQ $50-75$ or 75 , (c) trainable mentally retarded IQ $30-50$ or $35-55$, (d) dependent or profoundly mentally retarded with IQ in the 25 or 35 , (2) The medical-biological classification consists of (a) the degree of the border (IQ: 68-85), (b) mild disabled (IQ: 36-51), (c) moderate mental retardation (IQ: 35-20), and (d) disabled is very heavy with an IQ level below from 20. (3) Psychological classifications based on psychometric criteria consisting of (a) mild mental retardation) with IQ $=55-69$, (b) moderate mental retardation) with $\mathrm{IQ}=40-54$, (c) severe mental retardation with IQ $=20-39$, and (d) profound mental retardation) with IQ 20 and below.(4) A clinical classification which is classified on the basis of the following physical characteristics (a) down syndrome/mongoloid, (b) hydrocephalus is the size of a large head containing fluid, (c) microcephalus is too small head size and macrocephalus that is too large head size [4]. Based on the results of observation as a preliminary study conducted by researchers to children with mild mental retardation, it is obtained that its motoring ability is impaired and not as normal children in general especially the ability of fundamental movement skill. This is evident when they carry out the learning activities of physical education that the movements look awkward, lack the body balance so that they are difficult to control the position and have a less coordination of motion. After the initial observation turned out in addition to the motor capability of children disabled mild, there are disorders apparently their social activities are also impaired, this is evident from the less capable they interact among fellow, unstable emotions that require more mentoring. Therefore, adaptive physical education teachers are required to be more active and creative to modify the learning to be useful and meaningful for the child who is light. Looking at the characteristics of a child's mental retardation then in adaptive penjas? learning there must be elements of fun. Therefore, a play approach can be applied to the learning of adaptive Physical education. The form of games provided do not origin-asaln? or haphazardly, the games given must have a therapeutic element so as to improve their basic mobility skills. According to Prasedio in Efendi(2006) .[3] said that the game that can be given to the child of disabled at least has a charge, among others, has different therapeutic values as well as a given game figure and not too difficult to digest the child disabled. Departing from the problems, researchers are interested in doing a research on the child's mental retardation.. The title of research raised is "Play Activity: to Increase Fundamental movement skill For Children With Mild Mental Retardation.

\section{Methodology}

This study was conducted in three schools, namely Elementary School of Extraordinary School C Karyalbu, Elementary School of Extraordinary School C Yayasan Pembina AnakCacat (YPAC) and Elementary School of Extraordinary School B Pembina in the city of Palembang. The goal in this study is that students with child characteristics are mild mental retardation/capable of training/imbecilic that have an age between 7-12 years. The plan for the research of the play activity: to increase fundamental movement skill for mild mental retardation used the research \& development of Borg and Gall with ten steps/stages. The stages are as follows (1) research and information collecting, (2) planning, (3) develop primary form of product, (4) preliminary field, (5) main product revision, (6) main field testing, (7) operational product revision (8) operational field testing, (9) final product revision, (10) dissemination and implementation [2]. For more details can be seen figure 1 .

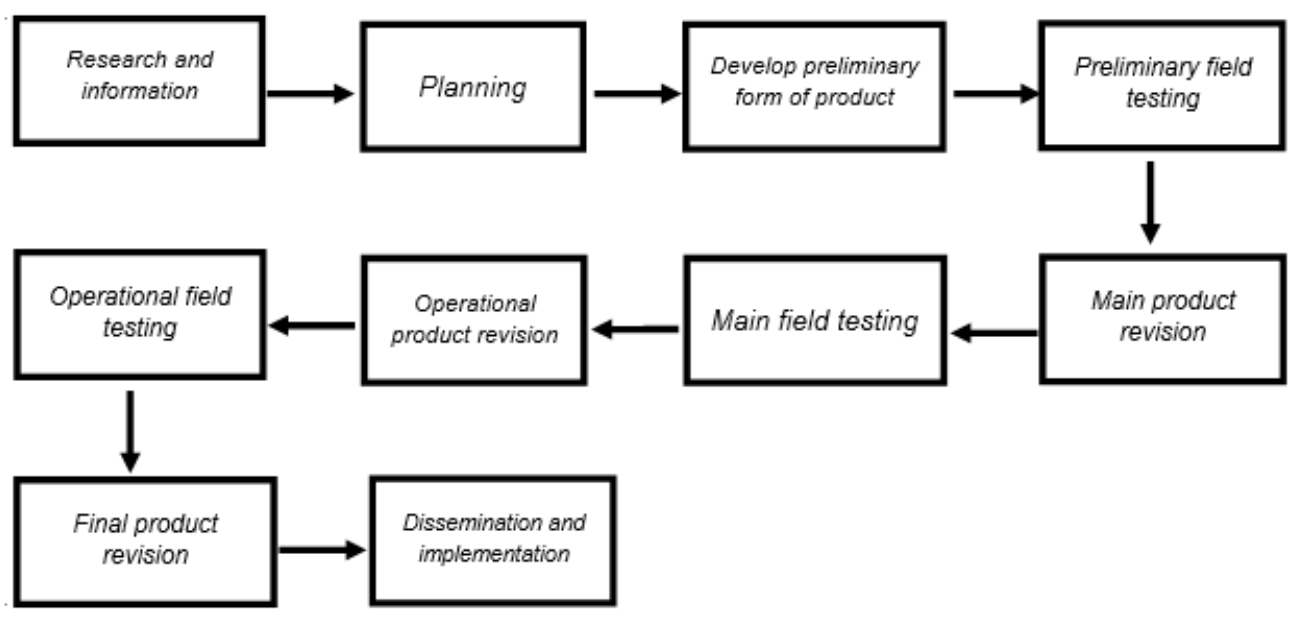

Figure 1. Instructional Design Research and Development 


\section{Result \& Discussion}

\subsection{Expert Judgment}

The expert evaluation consisted of 6 people with details for the adaptive physical education expert as many as 3 people and motorists as much as 3 people. The Draft product that has been made by researchers comprises 50 variations of fundamental movement skill. After being evaluated by experts turned out to be continued, namely 46 models and 4 variations are declared unworthy to continue.

Table 1. Result of Expert Evaluation

\begin{tabular}{|c|c|c|c|c|c|}
\hline \multirow{3}{*}{ No } & \multirow{3}{*}{ Model } & \multirow{2}{*}{\multicolumn{2}{|c|}{$\begin{array}{l}\text { Approved of Model } \\
\text { Expert PE and Expert } \\
\text { Motoric } \\
\end{array}$}} & \multirow{3}{*}{ (Feasible/No Feasible) } & \multirow{3}{*}{ Suggestion } \\
\hline & & & & & \\
\hline & & Yes & No & & \\
\hline \multicolumn{6}{|c|}{ LOCOMOTOR SKILL } \\
\hline \multicolumn{6}{|c|}{ Walking } \\
\hline 1. & Variation 1 & Yes & Yes & Feasible & Can be implemented \\
\hline 2. & Variation 2 & Yes & Yes & Feasible & Can be implemented \\
\hline 3. & Variation 3 & Yes & Yes & Feasible & Can be implemented \\
\hline 4. & Variation 4 & Yes & Yes & Feasible & Can be implemented \\
\hline 5. & Variation 5 & Yes & Yes & Feasible & Can be implemented \\
\hline \multicolumn{6}{|c|}{ Running } \\
\hline 1. & Variation 1 & Yes & Yes & Feasible & Can be implemented \\
\hline 2. & Variation 2 & Yes & Yes & Feasible & Can be implemented \\
\hline 3. & Variation 3 & Yes & Yes & Feasible & Can be implemented \\
\hline 4. & Variation 4 & Yes & Yes & Feasible & Can be implemented \\
\hline 5. & Variation 5 & Yes & Yes & Feasible & Can be implemented \\
\hline \multicolumn{6}{|c|}{ Leaping } \\
\hline 1. & Variation 1 & Yes & Yes & Feasible & Can be implemented \\
\hline 2. & Variation 2 & Yes & Yes & Feasible & Can be implemented \\
\hline 3. & Variation 3 & Yes & Yes & Feasible & Can be implemented \\
\hline 4. & Variation 4 & No & No & No Feasible & Difficult to do \\
\hline 5. & Variation 5 & Yes & Yes & Feasible & Can be implemented \\
\hline \multicolumn{6}{|c|}{ Dodging } \\
\hline 1. & Variation 1 & Yes & Yes & Feasible & Can be implemented \\
\hline 2. & Variation 2 & Yes & Yes & Feasible & Can be implemented \\
\hline 3. & Variation 3 & Yes & Yes & Feasible & Can be implemented \\
\hline 4. & Variation 4 & No & No & No Feasible & Difficult to do \\
\hline \multicolumn{6}{|c|}{ NON-LOCOMOTOR SKILL } \\
\hline \multicolumn{6}{|c|}{ Jumping } \\
\hline 1. & Variation 1 & Yes & Yes & Feasible & Can be implemented \\
\hline 2. & Variation 2 & Yes & Yes & Feasible & Can be implemented \\
\hline \multicolumn{6}{|c|}{ Foot Balances } \\
\hline 1. & Variation 1 & Yes & Yes & Feasible & Can be implemented \\
\hline 2. & Variation 2 & Yes & Yes & Feasible & Can be implemented \\
\hline \multicolumn{6}{|c|}{ Bottom Balances } \\
\hline 1. & Variation 1 & Yes & Yes & Feasible & Can be implemented \\
\hline 2. & Variation 2 & Yes & Yes & Feasible & Can be implemented \\
\hline
\end{tabular}


Table 1 Continued

\begin{tabular}{|c|c|c|c|c|c|}
\hline \multicolumn{6}{|c|}{ MANIPULATIVE SKILL } \\
\hline \multicolumn{6}{|c|}{ Small Ball Catch } \\
\hline 1. & Variation 1 & Yes & Yes & Feasible & Can be implemented \\
\hline 2. & Variation 2 & Yes & Yes & Feasible & Can be implemented \\
\hline 3. & Variation 3 & Yes & Yes & Feasible & Can be implemented \\
\hline 4. & Variation 4 & Yes & Yes & Feasible & Can be implemented \\
\hline 5. & Variation 5 & Yes & Yes & Feasible & Can be implemented \\
\hline \multicolumn{6}{|c|}{ Distance Throw } \\
\hline 1. & Variation 1 & Yes & Yes & Feasible & Can be implemented \\
\hline 2. & Variation 2 & No & No & No Feasible & Difficult to do \\
\hline 3. & Variation 3 & Yes & Yes & Feasible & Can be implemented \\
\hline 4. & Variation 4 & Yes & Yes & Feasible & Can be implemented \\
\hline 5. & Variation 5 & Yes & Yes & Feasible & Can be implemented \\
\hline \multicolumn{6}{|c|}{ Racquet Strike } \\
\hline 1. & Variation 1 & Yes & Yes & Feasible & Can be implemented \\
\hline 2. & Variation 2 & Yes & Yes & Feasible & Can be implemented \\
\hline 3. & Variation 3 & Yes & Yes & Feasible & Can be implemented \\
\hline \multicolumn{6}{|c|}{ Ball Strike } \\
\hline 1. & Variation 1 & Yes & Yes & Feasible & Can be implemented \\
\hline 2. & Variation 2 & Yes & Yes & Feasible & Can be implemented \\
\hline 3. & Variation 3 & Yes & Yes & Feasible & Can be implemented \\
\hline 4. & Variation 4 & Yes & Yes & Feasible & Can be implemented \\
\hline 5. & Variation 5 & Yes & Yes & Feasible & Can be implemented \\
\hline \multicolumn{6}{|c|}{ Large Ball Kick } \\
\hline 1. & Variation 1 & Yes & Yes & Feasible & Can be implemented \\
\hline 2. & Variation 2 & No & No & No Feasible & Difficult to do \\
\hline 3. & Variation 3 & Yes & Yes & Feasible & Can be implemented \\
\hline 4. & Variation 4 & Yes & Yes & Feasible & Can be implemented \\
\hline 5. & Variation 5 & Yes & Yes & Feasible & Can be implemented \\
\hline \multicolumn{6}{|c|}{ Hula Hoops } \\
\hline 1. & Variation 1 & Yes & Yes & Feasible & Can be implemented \\
\hline 2. & Variation 2 & Yes & Yes & Feasible & Can be implemented \\
\hline
\end{tabular}

\subsection{Product Revision I}

Once the product is validated by the expert then the product is repaired according to expert input/advice. The input from experts is to give input to equipment and supplies that are suitable for children with mild mental retardation, material content and implementation of the model.

\subsection{Small Group Test}

Small group trials were conducted at Elementary School SLB C Karyalbu with the number of research samples of 12 students with a mild mental retardation. The results of small group trials can be concluded that the product "can be used by children with mild mental retardation but still must be given instruction from the teacher/companion". 
Table 2. Result of Small Group Test

\begin{tabular}{|c|c|c|c|}
\hline No & Model & Suggestion/Recommendation & Explanation \\
\hline \multicolumn{4}{|c|}{ LOKOMOTOR SKILL } \\
\hline \multicolumn{4}{|c|}{ Walking } \\
\hline 1. & Variation 1 & Can be application with instruction & assessment rubric \\
\hline 2. & Variation 2 & Can be application with instruction & assessment rubric \\
\hline 3. & Variation 3 & Can be application with instruction & assessment rubric \\
\hline 4. & Variation 4 & Can be application with instruction & assessment rubric \\
\hline 5. & Variation 5 & Can be application with instruction & assessment rubric \\
\hline \multicolumn{4}{|c|}{ Running } \\
\hline 1. & Variation 1 & Can be application with instruction & assessment rubric \\
\hline 2. & Variation 2 & Can be application with instruction & assessment rubric \\
\hline 3. & Variation 3 & Can be application with instruction & assessment rubric \\
\hline 4. & Variation 4 & Can be application with instruction & assessment rubric \\
\hline 5. & Variation 5 & Can be application with instruction & assessment rubric \\
\hline \multicolumn{4}{|c|}{ Leaping } \\
\hline 1. & Variation 1 & Can be application with instruction & assessment rubric \\
\hline 2. & Variation 2 & Can be application with instruction & assessment rubric \\
\hline 3. & Variation 3 & Can be application with instruction & assessment rubric \\
\hline 4. & Variation 4 & Can be application with instruction & assessment rubric \\
\hline \multicolumn{4}{|c|}{ Dodging } \\
\hline 1. & Variation 1 & Can be application with instruction & assessment rubric \\
\hline 2. & Variation 2 & Can be application with instruction & assessment rubric \\
\hline 3. & Variation 3 & Can be application with instruction & assessment rubric \\
\hline \multicolumn{4}{|c|}{ NON-LOCOMOTOR SKILL } \\
\hline \multicolumn{4}{|c|}{ Jumping } \\
\hline 1. & Variation 1 & Can be application with instruction & assessment rubric \\
\hline 2. & Variation 2 & Can be application with instruction & assessment rubric \\
\hline \multicolumn{4}{|c|}{ Foot Balances } \\
\hline 1. & Variation 1 & Can be application with instruction & assessment rubric \\
\hline 2. & Variation 2 & Can be application with instruction & assessment rubric \\
\hline \multicolumn{4}{|c|}{ Bottom Balances } \\
\hline 1. & Variation 1 & Can be application with instruction & assessment rubric \\
\hline 2. & Variation 2 & Can be application with instruction & assessment rubric \\
\hline \multicolumn{4}{|c|}{ MANIPULATIVE SKILL } \\
\hline \multicolumn{4}{|c|}{ Small Ball Catch } \\
\hline 1. & Variation 1 & Can be application with instruction & assessment rubric \\
\hline 2. & Variation 2 & Can be application with instruction & assessment rubric \\
\hline 3. & Variation 3 & Can be application with instruction & assessment rubric \\
\hline 4. & Variation 4 & Can be application with instruction & assessment rubric \\
\hline 5. & Variation 5 & Can be application with instruction & assessment rubric \\
\hline \multicolumn{4}{|c|}{ Distance Throw } \\
\hline 1. & Variation 1 & Can be application with instruction & assessment rubric \\
\hline 2. & Variation 2 & Can be application with instruction & assessment rubric \\
\hline 3. & Variation 3 & Can be application with instruction & assessment rubric \\
\hline 4. & Variation 4 & Can be application with instruction & assessment rubric \\
\hline
\end{tabular}


Table 2 Continued

\begin{tabular}{clll}
\hline Racquet Strike & & & \\
\hline 1. & Variation 1 & Can be application with instruction & assessment rubric \\
\hline 2. & Variation 2 & Can be application with instruction & assessment rubric \\
\hline 3. & Variation 3 & Can be application with instruction & assessment rubric \\
\hline Ball Strike & & & assessment rubric \\
\hline 1. & Variation 1 & Can be application with instruction & assessment rubric \\
\hline 2. & Variation 2 & Can be application with instruction & assessment rubric \\
\hline 3. & Variation 3 & Can be application with instruction & assessment rubric \\
\hline 4. & Variation 4 & Can be application with instruction & assessment rubric \\
\hline 5. & Variation 5 & Can be application with instruction & assessment rubric \\
\hline Large Ball Kick & & assessment rubric \\
\hline 1. & Variation 1 & Can be application with instruction & assessment rubric \\
\hline 2. & Variation 2 & Can be application with instruction & assessment rubric \\
\hline 3. & Variation 3 & Can be application with instruction & \\
\hline 4. & Variation 4 & Can be application with instruction & assessment rubric \\
\hline Hula Hoops & & & assessment rubric \\
\hline 1. & Variation 1 & Can be application with instruction & Can be application with instruction
\end{tabular}

\subsection{Product Revision II}

The second revision was carried out after a small-scale trial. The inputs for revision are: (1) teacher and student assignments at the time of implementation, (2) a companion to assist the teacher's role, and (3) the companion may involve the student's parents.

\subsection{Large Group Test}

The large group trials were conducted in three elementary schools, namely the Elementary School of SLB C Karyalbu, Elementary School of SLB C YPAC and Elementary School SLB B Pembina in Palembang with a number of research samples of 60 students are light. The results of large group trials can be concluded that the product "can be used by all the children with mild mental retardation without guidance.

Table 3. Result of Large Group Test

\begin{tabular}{|c|c|c|c|}
\hline No & Model & Suggestion/Recommendation & Explanation \\
\hline \multicolumn{4}{|c|}{ LOKOMOTOR SKILL } \\
\hline \multicolumn{4}{|c|}{ Walking } \\
\hline 1. & Variation 1 & Can be application & assessment rubric \\
\hline 2. & Variation 2 & Can be application & assessment rubric \\
\hline 3. & Variation 3 & Can be application & assessment rubric \\
\hline 4. & Variation 4 & Can be application & assessment rubric \\
\hline 5. & Variation 5 & Can be application & assessment rubric \\
\hline \multicolumn{4}{|c|}{ Running } \\
\hline 1. & Variation 1 & Can be application & assessment rubric \\
\hline 2. & Variation 2 & Can be application & assessment rubric \\
\hline 3. & Variation 3 & Can be application & assessment rubric \\
\hline 4. & Variation 4 & Can be application & assessment rubric \\
\hline 5. & Variation 5 & Can be application & assessment rubric \\
\hline
\end{tabular}


Table 3. Continued

\begin{tabular}{|c|c|c|c|}
\hline \multicolumn{4}{|c|}{ Leaping } \\
\hline 1. & Variation 1 & Can be application & assessment rubric \\
\hline 2. & Variation 2 & Can be application & assessment rubric \\
\hline 3. & Variation 3 & Can be application & assessment rubric \\
\hline 4. & Variation 4 & Can be application & assessment rubric \\
\hline \multicolumn{4}{|c|}{ Dodging } \\
\hline 1. & Variation 1 & Can be application & assessment rubric \\
\hline 2. & Variation 2 & Can be application & assessment rubric \\
\hline 3. & Variation 3 & Can be application & assessment rubric \\
\hline \multicolumn{4}{|c|}{ NON-LOCOMOTOR SKILL } \\
\hline \multicolumn{4}{|c|}{ Jumping } \\
\hline 1. & Variation 1 & Can be application & assessment rubric \\
\hline 2. & Variation 2 & Can be application & assessment rubric \\
\hline \multicolumn{4}{|c|}{ Foot Balances } \\
\hline 1. & Variation 1 & Can be application & assessment rubric \\
\hline 2. & Variation 2 & Can be application & assessment rubric \\
\hline \multicolumn{4}{|c|}{ Bottom Balances } \\
\hline 1. & Variation 1 & Can be application & assessment rubric \\
\hline 2. & Variation 2 & Can be application & assessment rubric \\
\hline \multicolumn{4}{|c|}{ MANIPULATIVE SKILL } \\
\hline \multicolumn{4}{|c|}{ Small Ball Catch } \\
\hline 1. & Variation 1 & Can be application & assessment rubric \\
\hline 2. & Variation 2 & Can be application & assessment rubric \\
\hline 3. & Variation 3 & Can be application & assessment rubric \\
\hline 4. & Variation 4 & Can be application & assessment rubric \\
\hline 5. & Variation 5 & Can be application & assessment rubric \\
\hline \multicolumn{4}{|c|}{ Distance Throw } \\
\hline 1. & Variation 1 & Can be application & assessment rubric \\
\hline 2. & Variation 2 & Can be application & assessment rubric \\
\hline 3. & Variation 3 & Can be application & assessment rubric \\
\hline 4. & Variation 4 & Can be application & assessment rubric \\
\hline \multicolumn{4}{|c|}{ Racquet Strike } \\
\hline 1. & Variation 1 & Can be application & assessment rubric \\
\hline 2. & Variation 2 & Can be application & assessment rubric \\
\hline 3. & Variation 3 & Can be application & assessment rubric \\
\hline \multicolumn{4}{|c|}{ Ball Strike } \\
\hline 1. & Variation 1 & Can be application & assessment rubric \\
\hline 2. & Variation 2 & Can be application & assessment rubric \\
\hline 3. & Variation 3 & Can be application & assessment rubric \\
\hline 4. & Variation 4 & Can be application & assessment rubric \\
\hline 5. & Variation 5 & Can be application & assessment rubric \\
\hline \multicolumn{4}{|c|}{ Large Ball Kick } \\
\hline 1. & Variation 1 & Can be application & assessment rubric \\
\hline 2. & Variation 2 & Can be application & assessment rubric \\
\hline 3. & Variation 3 & Can be application & assessment rubric \\
\hline 4. & Variation 4 & Can be application & assessment rubric \\
\hline \multicolumn{4}{|c|}{ Hula Hoops } \\
\hline 1. & Variation 1 & Can be application & assessment rubric \\
\hline 2. & Variation 2 & Can be application & assessment rubric \\
\hline
\end{tabular}




\subsection{Final Product}

Field trials show that the model of play activity: to increase fundamental movement skill can be applied and can be done by students with mild mental retardation. Therefore, nothing else should be revised because it has fulfilled the required aspect of the standard so that the product is worth using.

\subsection{Model Effectiveness}

Effective test was carried out in three schools, namely Elementary School of SLB C KaryaIbu, Elementary School of SLB YPAC and Elementary School of SLB B Pembina Kota Palembang, amounting to 60 students by giving the treatment of basic motion-based models for children with mild mental retardation. For more details can be found below: a). Locomotor test, the test results show that there is a significant difference between before and after the treatment is given. Judging from the result Mean = 2.35517 where $t_{\text {count }}>t_{\text {table }}$ is $14.357>2.000$.

b). Non locomotor test, the test results show that there is a significant difference between before and after the treatment is given. Judging from the result Mean = -1.72500 where $t_{\text {count }}>t_{\text {table }}$ is $-24.175>2.000$.

c). Manipulative test/object control test, the test results show that there is a significant difference between before and after the treatment is given. Judging from the result Mean $=-4.533$ where $\mathrm{t}_{\text {count }}>\mathrm{t}_{\text {table }}$ is $-23.754>$ 2,000 .

The test results showed that there was a significant increase. So, it can be concluded that model play activity: to increase fundamental movement skill for children with mild mental retardation effective and feasible, so that it can be used by children with mild mental retardation.

Table 4. Locomotor Test

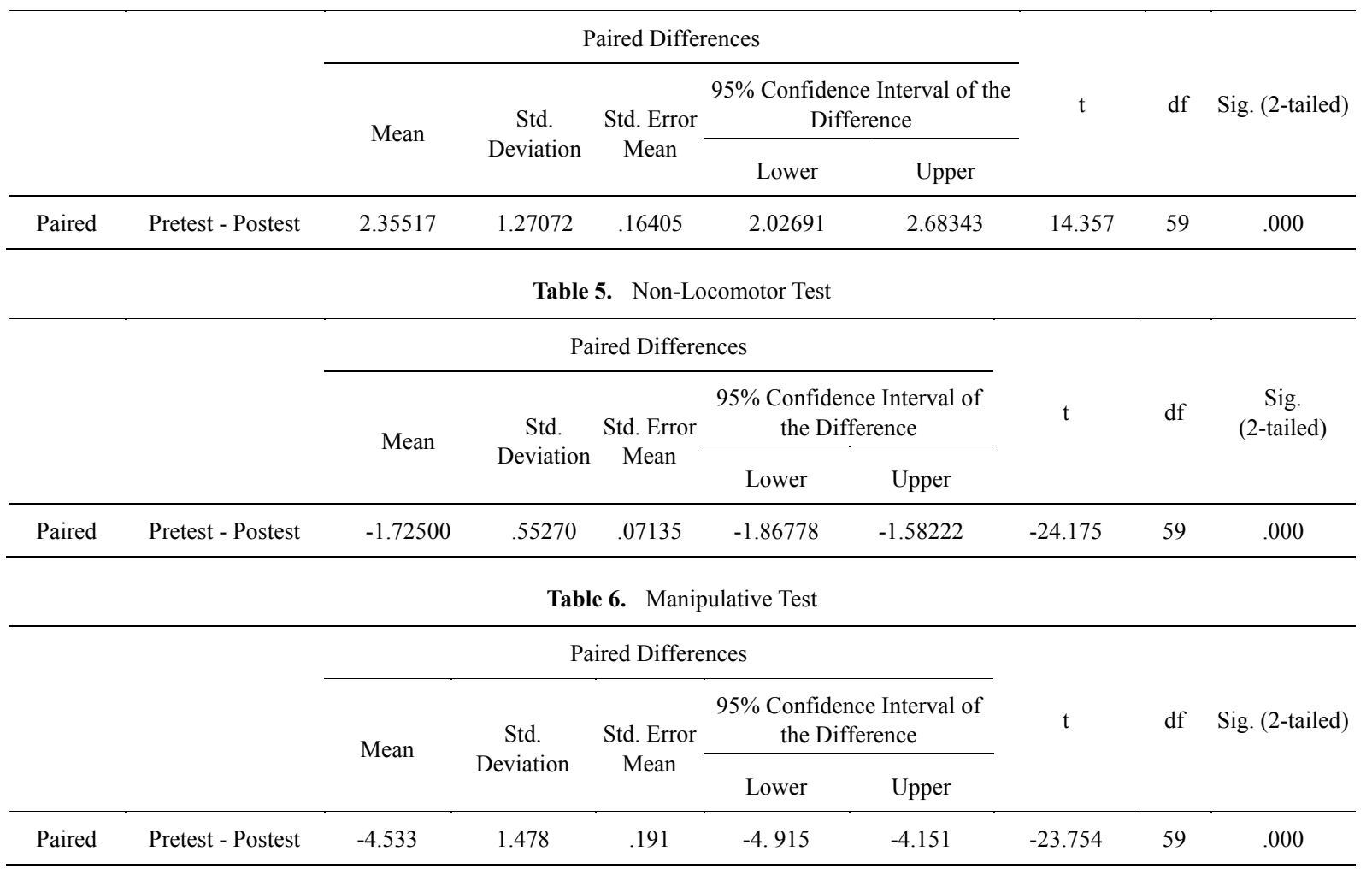




\subsection{Discussions}

Play activity: to increase fundamental movement skill for children with mild mental retardation in this research was declared feasibly and effectively used by children with mental retardation. It is feasibly worthy because it has been tested (small group test and large group test) and evaluated by experts judgment (physical education, motor and mental retardation), hereinafter stated to be effectively used based on effective tests. This research also shows that the results through a play approach will make it easier for children to follow the activity of motion taught because in playing there is a feeling of delight and a sense of contentment that is unconscious and also by it they can develop other aspects of development besides physical development. Looking at the results of the above research stating that activities/play activities are one of the right ways to provide of material fundamental movement skills then it is in line with some opinions of which are according to Astuti in Mumpuniarti that said that the game is as an effort to help children to make the physical, intellectual, emotional and social aspects optimally [6]. Furthermore, according to Cratty in Mulyono that motion games in helping children with learning problems and movement activities can provide a sensory experience that can show the performance of learning in a common way in class [5]. According to Tedjasaputra, the play is "a useful experience for development that is beneficial to: (1) The development of physical aspects; (2) Development of motor aspect; (3) Social aspect development; (4) Development of aspect of emotional/personality;(5) Developmental aspects of cognition; (6) Sharpen sensing sharpness; (7) Develop sports and dancing skills " [8]. Actually playing is a means of natural actualisation that exists in every human being. In addition to the means of an indirect actualization play, it can make one get the freshness and fitness both physically and spiritually. For the child, especially mental retardation in this research of the playing activity should be more optimized. Elements of fun feeling and the form of an easy game are possible to achieve the ultimate goal of a learning that is beneficial to the child mild mental retardation. The research fundamental movement skill-based games conducted by researchers were strengthened by the research from Yuniar Indah Utari and Nanik Indahwati who said that through traditional games can increase the fundamental movement skill of the locomotor child with mild mental retardation. The research indirectly replied that the approach to play can be used as a means to enhance the fundamental movement skill for child with mild mental retardation [9]. What distinguishes is the research conducted by researchers focuses more on the overall fundamental movement skill of locomotor, non-locomotor and manipulative. To be able to implement a learning model well and to be the defining success of learning, then you are the leader of the forefront of implementing it.
In the context of learning for a child, in this research, the child has a mild mental retardation that learning should be prepared with the principles of specificity or individual principles. So a teacher should be able to develop a curriculum that exists according to the needs of the child's own mild mental retardation. In this research, it is related to motor especially fundamental movement skill of the child mild mental retardation. The condition is in line with the opinion of Kemis and Ati that the teacher has a strategic position and determines the success of learning, because the function of the teacher is the designer, organizer and evaluator of the entire learning process so that eventually the real will determine the depth and breadth of the material to be taught to each participant, because the teacher can be able to select and choose the material that is as good as the obstacles, problems and learning needs of each individual to be educated. More clearly according to Kemis and Ati that there are two principles in conveying learning for the child, namely (1) General principles consist of: Principles of motivation, background/context, direction, social relations, study while working, individualization, finding and Problem solving, (2) Special Principles for children with mental retardation namely principles of love, compassion, habilitation (habituations) and rehabilitation (improvement) [4]. From the results of the research and theory that by playing can be used as an approach in providing learning or training in this case related to the fundamental movement skill. Playing in addition to the stimulus of psychomotor to stimulate children, can also stimulate cognitive and attitude/affective for the child with mental retardation. In addition, in order to convey the material well, it should be understood the character of disabled children because the child has a slow understanding and a diverse ego that requires being given more attention and supervision to. Therefore, for further study the model is expected based on difficulty level to facilitate for teachers, trainers, elders and students.

\section{Conclusions}

The conclusion in this research is to produce a product in the form of a play activity: to increase fundamental movement skill for children with mild mental retardation. This Model can be applied during learning and training fundamental movement skill because it is through a play approach. Can be applied to this has been tested for effectiveness, where the test-t results indicate a significant increase.

\section{REFERENCES}

[1] Armatas, V, Mental Retardation: definitions, etiology, 
epidemiology and diagnosis. Aristotle University of Thessaloniki, Grece : Journal of Sport and Health Research, vol 1, no. 2, pp. 112-122, 2009.

[2] Bog, W.R. \& Gall, M.D, Educational Research An Introduction. Longman : New York, pp. 775, 2007.

[3] Effendi, Pengantar Psikopedagogik Anak Berkelainan, Jakarta :BumiAksara, pp. 105, 2006.

[4] Kemis \& Rosanawati, Ati, Pendidikan Anak Berkebutuhan Khusus Tunagrahita, Jakarta : PT. Luxima Metro Media, pp 1-15 and pp. 84-85, 2013.

[5] Mulyono, Abdurrachman, Pendidikan Bagi Anak Berkesulitan Belajar. Jakarta :RinekaCipta, 2003.

[6] Mumpuniarti, Penanganan Anak Tunagrahita (Kajian Dari
Segi Pendidikan, Sosial-Psikologis dan Tindak Lanjut Usia Dewasa). Yogyakarta : FIP UNY, pp. 118, 2000.

[7] Sri Widati, $\mathrm{CH}$ and Murtadlo, Pendidikan Jasmani dan Olahraga Adaptif. Jakarta: Departemen Pendidikan Nasional Direktorat Jenderal Pendidikan Tinggi Direktorat Ketenagaan, pp. 261, 2007.

[8] Tedja Saputra, Mayke S, Bermain, Manandan Permainan. Jakarta : Grasindo, pp. 30-45, 2001.

[9] Utari, Yuniar Indah \&Indah wati, Nanik, Upaya Meningkatkan Gerak Dasar Lokomotor Anak Tunagrahita Ringan Melalui Permainan Tradisional (Pada Siswa-Siswi Sekolah Dasar Luar Biasa Tunas Mulya Surabaya. Jurnal Pendidikan Olahraga dan Kesehatan, vol. 3, no. 2, pp. 279-282, 2015. 